\title{
Wireless MEMS-based system for real-time geotechnical instrumentation of active slopes
}

\author{
T. Abdoun ${ }^{1}$, V. Bennett ${ }^{1}$, S. Thevanayagam ${ }^{2}$, R. Dobry ${ }^{1}$, \\ T. Shantz ${ }^{3} \&$ D. Jang ${ }^{3}$ \\ ${ }^{I}$ Department of Civil and Environmental Engineering, \\ Rensselaer Polytechnic Institute, USA \\ ${ }^{2}$ Department of Civil and Environmental Engineering, \\ University at Buffalo, USA \\ ${ }^{3}$ California Department of Transportation, USA
}

\begin{abstract}
Landslides, lateral spreading and other similar forms of ground failures due to natural disasters, such as heavy rains, floods and earthquakes, continue to be catastrophic events with extreme economic and societal costs, despite our increased understanding of the mechanisms of failure and large ground deformation, primarily because these events occur without much warning. Realtime monitoring programs are essential to develop warning systems of impending danger from active landslides in any site specific or regional hazard program. Unfortunately the current state-of-the-art in real-time monitoring of active slopes is either based on very expensive monitoring systems or on measurement of ground surface displacements. The work presented in this paper is a major step in the direction of establishing autonomous monitoring technology for soil and soil-structure systems. The MEMS-based in-place inclinometer system, ShapeAccelArray (SAA), is capable of simultaneously measuring 3D soil acceleration and 3D permanent ground deformation up to a depth of one hundred meters, with an accuracy of $\pm 1.5 \mathrm{~mm}$ per $30 \mathrm{~m}$. Each sensor array is connected to a wireless sensor node to enable real-time monitoring as well as remote sensor configuration. This paper presents a brief description of the design of this sensor array and results from full-scale liquefaction and lateral spreading testing, as well as preliminary results from field tests of an active slope in California aimed at validating the measured accelerations and displacements.
\end{abstract}

Keywords: instrumentation, early warning, sensor array, MEMS. 


\section{Introduction}

Ground failure, landslides and damage to geotechnical systems due to earthquake excitations impact all seismically active areas around the world. The associated mechanisms of ground response are being documented through a worldwide network of sites instrumented with vertical downhole accelerometer arrays, often supplemented at liquefiable sites with pore pressure piezometers and in some cases with slope inclinometer arrays. In the United States, early vertical array data sets were recorded at the San Francisco Bay area (Joyner et al. [1], Johnson and Silva [2]) and at Union Bay in Seattle (Seed and Idriss [3], Dobry et al. [4]). During the 1980s, data from seismic arrays that include pore-pressure piezometers became available such as data from the Wildlife Refuge site in California, (Holzer et al. [5]). To monitor lateral spreading and possible slope failures of active grounds, state Departments of Transportation and other agencies also use in-place slope inclinometer arrays. These arrays can provide real-time monitoring with good angular resolution capability; however, they are expensive and inflexible. This high cost makes it impractical to install multiple arrays on a single slope, thus severely limiting the ability of conducting comprehensive real-time monitoring.

Soil-structure systems and natural soil deposits exhibit a broad range of complex response patterns when subjected to dynamic loading conditions (NRC [6], Arulanandan and Scott [7]). Some of these patterns reflect local mechanisms associated with the particulate nature of soils, and others are related to abrupt changes in properties. Our understanding of the mechanisms of soil dynamic response, large deformation and failure due to earthquakes has improved considerably over the last two decades. However, significant challenges remain in modeling soils response when subjected to large deformations and ground failure. This state of affairs stems partly from limitations of existing monitoring tools and system identification techniques. Thus, computational soil models generally have somewhat restricted predictive capabilities for severe loading conditions, as these models remain to be validated using adequate case history data. For instance, the lack of accurate measurements of permanent deformation is one of the factors that hinder the development of soil models capable of reliably predicting site lateral spreading induced by seismic excitations.

This paper presents: (1) a brief description of the design of the ShapeAccelArray (SAA) system for monitoring the acceleration and permanent deformation of soil and soil-structure systems, (2) data comparisons between SAAs and traditional instrumentation utilized in a full-scale sloping-ground test at the University at Buffalo's $6 \mathrm{~m}$ high laminar container, and (3) preliminary results from a field installation of the SAA system at an active slope in California.

\section{Sensor description}

The ShapeAccelArray (SAA) system uses temperature-calibrated MEMS accelerometers within $30 \mathrm{~cm}$ long rigid segments connected by composite joints 
that prevent torsion but allow flexibility in two degrees of freedom. The SAAs are factory-calibrated and completely sealed, requiring no field assembly or calibration. Because each segment of the SAA contains three orthogonal sensors, arrays can be installed vertically or horizontally. The intended array orientation does not need to be specified prior to installation. Orientation can be selected in the accompanying software. Each sensor has an output that is the sine of the angle of tilt over a range of 360 degrees. The sensor arrays arrive at the jobsite on an $86 \mathrm{~cm}$ diameter reel, see Figure 1, and can be lowered into vertical, or pushed into horizontal, $25 \mathrm{~mm}$ casing. The initial shape of the installation, or the absolute deviation of the installation from a virtual vertical or horizontal line, can be immediately viewed on a computer. An SAA is modeled as a virtual multisegment line in the software, with $\mathrm{x}, \mathrm{y}$, and $\mathrm{z}$ data representing the vertices of this polyline. In the case of near-vertical installations, the vertices correspond to the joint-centers of the array in 3D. For near-horizontal installations, the vertices show vertical deformation only versus horizontal position (Abdoun et al. [8]; Bennett et al. [9]).

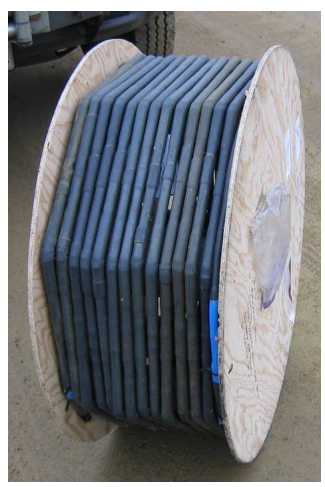

Figure 1: $\quad 32 \mathrm{~m} \mathrm{SAA}$ on shipping reel.

Wireless SAA data transmission is made possible by the use of an on-site data acquisition system, called a wireless earth station. Similar to traditional probe and in-place inclinometers, data from the SAA represents deviations from a starting condition or initial reading. These data are sent wirelessly, over a cellular telephone network, to an automated server, where data are made available to users through proprietary viewing software and an internet connection. Longterm system automated monitoring using SAAs typically collects data once or a few times a day but this collection frequency can be re-specified remotely by the user and changed at any time, through the same wireless interface used to receive the data. The SAA system is capable of collecting data at a sampling frequency rate of up to $128 \mathrm{~Hz}$, which makes it suitable for dynamic and seismic measurement. Each array is equipped with a trigger sensor that would automatically switch the SAA from slow to fast sampling rate in the case of a seismic event. Limiting the use of fast sampling rates to specific dynamic events 
significantly reduces the power consumption as well as data storage and transmission requirements.

\section{Full-scale laminar container tests}

Researchers at the University at Buffalo (UB) and Rensselaer Polytechnic Institute (RPI) studying earthquake-induced soil-liquefaction and its effects on foundations that support waterfront infrastructure developed a large-scale earthquake simulator to model the response of saturated sand to earthquake forces. The earthquake simulator is part of the NEES@Buffalo equipment and research site, a National Science Foundation (NSF) facility. The laminar container at the University at Buffalo is $5 \mathrm{~m}$ long, $2.75 \mathrm{~m}$ wide and $6 \mathrm{~m}$ high and is capable of containing 150 tons of sand, see Figure 2.
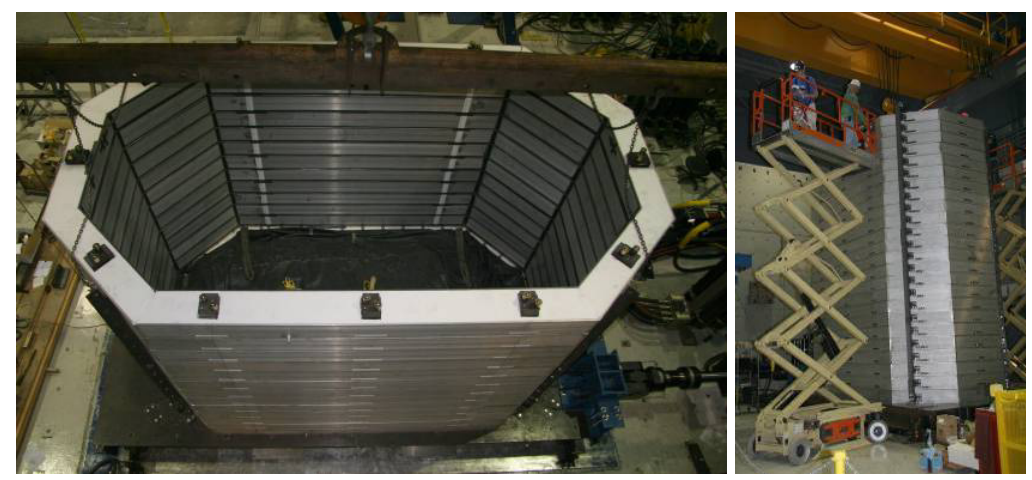

Figure 2: Assembly of laminar container at the University at Buffalo.

Specially designed ball bearings are used between each of the $0.254 \mathrm{~m}$ thick laminar rings to achieve nearly frictionless sliding. After filling the container with loose sand and water, two 100-ton hydraulic actuators were used to input pre-determined motion with a $2 \mathrm{~Hz}$ frequency to the base of the box. The resultant soil liquefaction and lateral spreading was monitored using accelerometers within the deposit and on the laminates, LVDTs on the laminates, pore-pressure transducers and two SAAs within the soil deposit, see Figure 3. The results from one of two $7 \mathrm{~m}$ long SAAs installed in a sloping ground test, where the base of the box was inclined $2^{\circ}$, are presented herein. Each of these sensor arrays contained $243 \mathrm{D}$ sensing elements. One of these sensor arrays was placed in the center of the laminar container and a second array was $1 \mathrm{~m}$ east of the center, along the centerline of the container. Traditional instrumentation included variable capacitance accelerometers within the soil and on the rings and potentiometers (displacement sensors) on the rings.

Since the sensor arrays were $1 \mathrm{~m}$ longer than the height of the laminar container, the excess length was fastened to a frame above the box with elastic connections. Complementary experimental and numerical simulations conducted prior to this sloping ground test predicted $50 \mathrm{~cm}$ of permanent lateral 
displacement. Thus, the top of the SAAs were fixed approximately $25 \mathrm{~cm}$ downslope, in an effort to lessen any restrictive effects from the top of the array on the rest of the sensor array within the soil. Arrays were fixed at the bottom of the container with a two-point clamp to provide a reference end and were installed prior to the soil placement.

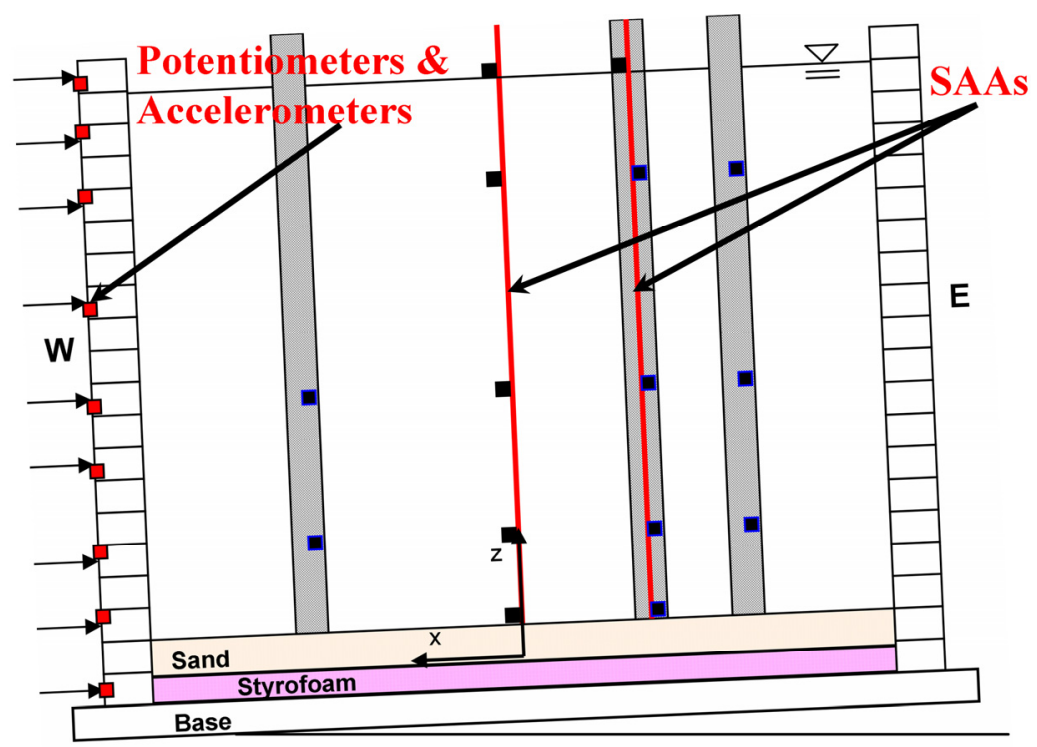

Figure 3: Layout of instrumentation within container and on laminar rings.

The acceleration and lateral displacement data from the SAA compared to the ring accelerometer and potentiometer data, respectively, are presented in Figure 4. At the end of the input shaking event, nearly the whole soil deposit was liquefied, and the ground surface displacement had reached $32 \mathrm{~cm}$, as seen in Figure 4.

Some discrepancies are observed between the SAA data and the ring accelerometer data after $6 \mathrm{~s}$, which is when the soil deposit began to liquefy. As the soil liquefied, the upper part of the SAA moved downslope with respect to the bottom of the array, thus the accelerometers were tilted with respect to their initial condition. This resulted in a slight DC component bias in the SAA acceleration readings. By filtering this low frequency component, the acceleration readings from both types of instrumentation would match even more closely. Since this was a dynamic test, the dynamic component of the displacement was removed by filtering to obtain the results presented in Figure 4. This full-scale lateral spreading experiment provides a unique example of the simultaneous acceleration and permanent lateral displacement data capture provided by the SAA system. For more information on this full-scale experiment see Dobry et al. [10]. 

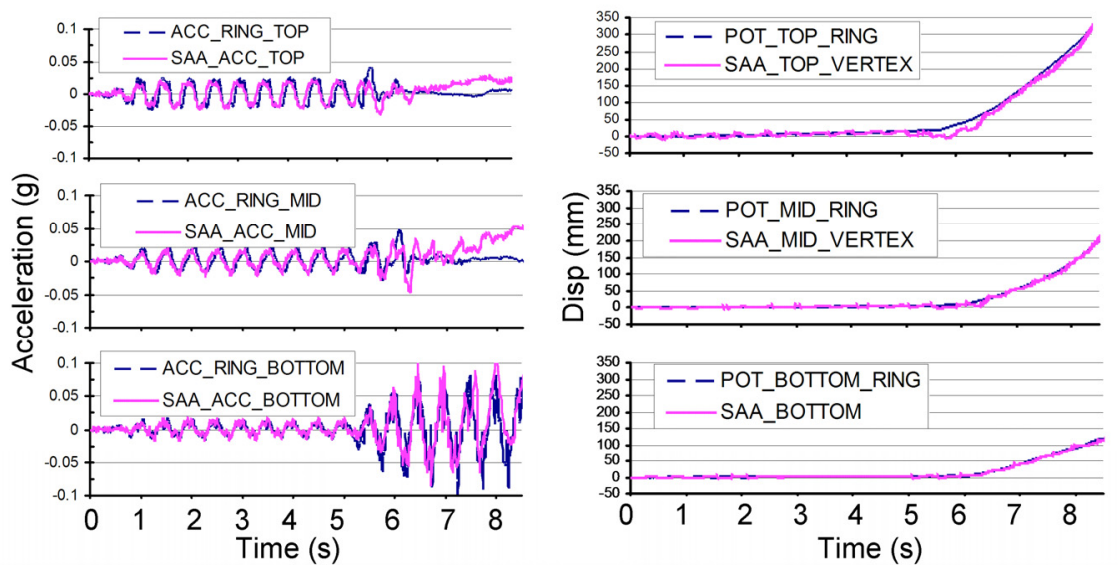

Figure 4: Lateral acceleration and displacement from one SAA system and traditional accelerometers and potentiometers.

\section{Unstable slope monitoring with SAA system}

In June 2006, a 20 m SAA was installed in an unstable slope in California, which has been documented as an ancient landslide prone area, $225 \mathrm{~m}$ long and $100 \mathrm{~m}$ wide, by Caltrans' geotechnical site reports.

This installation was conducted to validate the in situ displacement measurements collected by the SAA system in this landslide and lateral spreading monitoring application. Four conventional probe inclinometer casings were installed at the highway level, through this region, from 2002 to 2005, and ground deformations were large enough to shear some of these casings. The SAA was installed approximately $1 \mathrm{~m}$ away from a new inclinometer casing installation. Threaded $3 \mathrm{~m}$ long sections of $7.6 \mathrm{~cm}$ diameter inclinometer casing were used to house the SAA in a $12.7 \mathrm{~cm}$ diameter borehole. The annulus between the SAA and the casing was backfilled with coarse sand. This backfill was compacted, to the extent possible, by striking the side of the casing with a mallet during the sand placement (Abdoun et al. [8]). This method of installation has been superseded by direct installation of the SAA in grouted $25 \mathrm{~mm}$ casing due to concerns about sand bridging. Figure 5 shows a comparison of SAA data with conventional probe inclinometer data for a nine month monitoring period. The National Weather Service reported that the amount of rainfall during the 2006-2007 rain season in this area of California was nearly $30 \mathrm{~cm}$ below the average and the recorded ground deformations are correspondingly low, less than $10 \mathrm{~mm}$. However, the trends are visible and comparable. Wireless field data from three SAA systems, including this installation, indicate an array repeatability of better than $+/-1.5 \mathrm{~mm}$ in $32 \mathrm{~m}(0.05 \mathrm{~mm} / \mathrm{m})$ over long periods of time (more than two years) and hundreds of readings, in non-moving portions of the soil. 


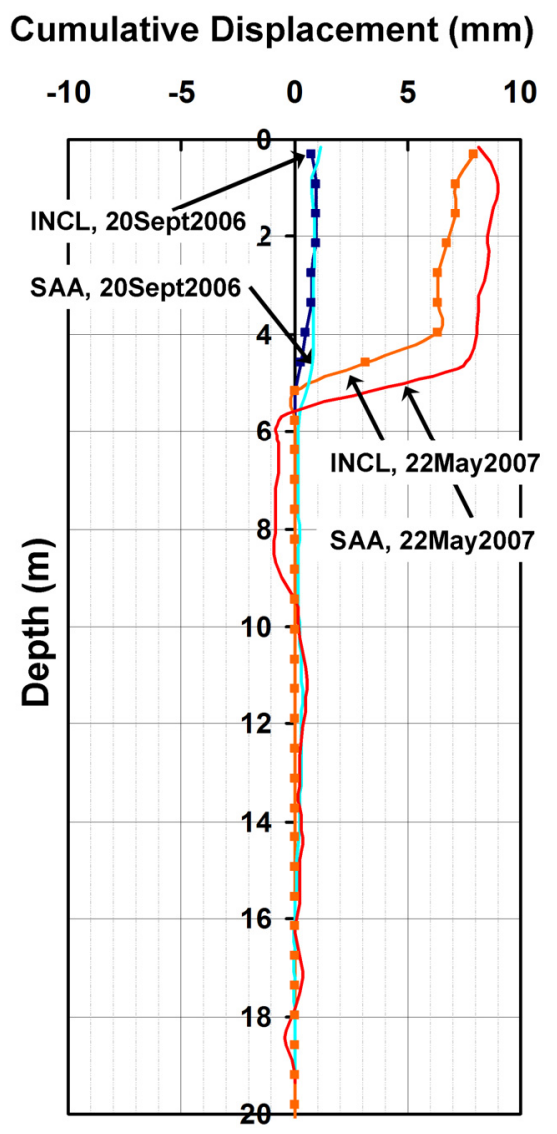

Figure 5: $\quad$ Unstable slope ground deformations at California test site.

\section{Conclusions}

The work presented in this paper constitutes a major step toward autonomous monitoring technology for soil systems susceptible to earthquakes and lateral spreading. The wireless ShapeAccelArray (SAA) is currently being further developed for in situ and research applications, taking advantage of the continuous advances in Micro-Electro-Mechanical Systems (MEMS) and wireless networking technologies. These preliminary full scale test results demonstrate that the SAA system is capable of simultaneously and accurately measuring acceleration and permanent ground deformation in situ. Based on the excellent agreement between SAA and traditional sensor data in both full-scale testing and field installations, the SAA data is currently being utilized in system identification techniques and for further investigation of the lateral spreading mechanism. 


\section{References}

[1] Joyner, W.B., Warrick, R.E., \& Oliver, A.A., Analysis of Seismograms from a Downhole Array in Sediments near San Francisco Bay. Bulletin of the Seismological Society of America, 66(4), pp. 937-958, 1976.

[2] Johnson, L.R., \& Silva, W., The Effects of Unconsolidated Sediments Upon the Ground Motion During Local Earthquakes. Bulletin of the Seismological Society of America, 71(1), pp. 127-142, 1981.

[3] Seed, H.B. \& Idriss, I.M., Analyses of Ground Motion at Union Bay, Seattle during Earthquakes and Distant Nuclear Blasts. Bulletin of the Seismological Society of America, 60(1), pp. 125-136, 1970.

[4] Dobry, R., Whitman, R.V., \& Roesset, J.M., Soil Properties and the OneDimensional Theory of Earthquake Amplification. Research Report R7118, School of Engineering, Massachusetts Institute of Technology, 1971.

[5] Holzer, T.L., Youd, T.L., \& Hanks, T.C., Dynamics of Liquefaction during the 1987 Superstition Hills, California Earthquake. Science, 244(1), pp. 5659, 1989.

[6] NRC. Earthquake Engineering Research - 1982, Overview and Recommendations. Report by the Committee on Earthquake Engineering, National Research Council, National Academy Press. Washington, D.C., 1982.

[7] Arulanandan, K. \& Scott, R.F., eds. Verification of Numerical Procedures for the Analysis of Soil Liquefaction Problems, Vol. 1, Balkema, Davis, CA, 1993.

[8] Abdoun, T., Bennett, V., Danisch, L., Shantz, T., \& Jang, D., Field installation details of a wireless shape-acceleration array system for geotechnical applications. Proceedings of SPIE, San Diego, CA, March 1922, Volume 6529, 2007.

[9] Bennett, V., Abdoun, T., Shantz, T., Jang, D., \& Thevanayagam, S., Design and Characterization of a Compact Array of MEMS Accelerometers for Geotechnical Instrumentation. Smart Structures and Systems Journal (under review), 2009.

[10] Dobry, R. et al., Mechanics of Lateral Spreading Observed in a Full-Scale Shake Test. Journal of Geotechnical and Geoenvironmental Eng., ASCE, (under review), 2009. 